\title{
The JAAS community: we few, we lucky few, we band of brothers
}

I was going to entitle this Editorial either "Cite me to the end of love" or "Everybody knows the dice are loaded", in memory of Leonard Cohen, who sadly passed away as I was working on it. As you can guess, my original focus was going to be on metrics and citations. However, I realized while writing it, that there are aspects much more important for us, all people related to JAAS, than those numbers. Thus, I will not discuss them (too much). Of course we are happy to see that, after 31 years of life, JAAS is a mature Journal, with an evolving but clear scope ${ }^{1}$ and it is still firmly positioned in the Q1 section of both Analytical Chemistry and Spectroscopy categories, despite the constant evolution of the field, and the appearance of many competing Journals. It is interesting to notice that the first Journals in the Spectroscopy area are all review Journals, who have obvious advantages in terms of impact factor, while the first Journals in the Analytical Chemistry category tend to be occupied by Journals with a broader scope that publish many articles per year.

JAAS follows a different approach. We are compelled to publish the best original research, as well as meaningful review articles, produced by the community of atomic spectroscopists and related scientists. We believe that a Journal with such scope, publishing over 200 articles per year, still is the right tune for many of us. ${ }^{2}$ In a changing world, where personal metrics (h-index, nindex) are becoming even more relevant that Journal metrics for every particular author, it is important to publish your research in a venue that reaches the right public, who will value it properly. Otherwise, it is not uncommon to see good articles from our area getting published in broader Journals, where they may not receive all the attention/citations that they probably deserve.

Our goal is to further strengthen the allegiance of JAAS with our community, and we have taken a number of initiatives in that regard over the last years, which perhaps are worth mentioning. In the first place, I would like to stress our sincere compromise with the young scientists, who will cement the future of our field. JAAS is publishing in summer 2017 the $5^{\text {th }}$ Themed issue devoted to Young analytical scientists, edited by Dr. Jorge Pisonero, from the University of Oviedo. It seems only yesterday when I was so proud to be selected for the first of such issues in 2002! Young authors who contribute to this issue must be corresponding authors of their manuscripts. The $4^{\text {th }}$ issue was published in $2014 .^{3}$

Moreover, in 2015 and coinciding with the 30th anniversary of the journal, the JAAS Emerging Investigator Lectureship Award was launched. This lectureship is awarded annually to recognize and support an emerging scientist working in the area of atomic spectrometry in the early stages of their independent career. The recipients of the lectureship will receive support to present their research at a relevant high-profile international meeting, together with a certificate and an invitation to contribute a Perspective or Research Article to JAAS. The inaugural Award was shared between Dr. Lara Lobo Revilla, from the University of Oviedo and Dr. Gerardo Gamez, from Texas Tech University. ${ }^{4}$ In 2016, the Awardee has been Dr. Sohail Mushtaq, from London Metropolitan University. ${ }^{5}$ He will receive his Award in June 2017 in Pisa, during the Colloquium Spectroscopicum 
Internationale XL. ${ }^{6}$

In addition to this issue devoted to young authors, we will like to honor the memory of the former Chair of JAAS and Metallomics, our friend and mentor, the late Dr. Joseph A. Caruso, with a joint Themed Issue between both Journals that will be edited by Gary Hieftje, from Indiana University and María MontesBayón, from the University of Oviedo. We will use the web collection format, which enables us to have more flexibility regarding time, and also permits the collection to grow over time.

We are also thinking of new ways to thank our referees for their indispensable help. Only thanks to their commitment it is feasible to keep the Journal running, with an average time of less than 60 days, from the reception to the acceptance of a manuscript. We want to express our sincere gratitude to all of them and particularly acknowledge the most prolific ones, who have been recently listed in the JAAS blog. ${ }^{7}$

And we are always eager to meet authors, referees and scientists in general. We'll do our very best to ensure that members of the JAAS Editorial Office and/or the Editorial Board are present at every major conference where atomic spectrometry is represented. In 2017, you can easily find some of us at the European Winter Conference on Plasma Spectrochemistry (a Themed issue devoted to this conference will be published in summer), the Pittcon, the 14th Rio Symposium on Atomic Spectrometry, the above mentioned Colloquium Spectroscopicum Internationale XL or the SciX conference, to name some of the symposiums we will be attending.

We hope to meet you in one of these conferences, or hear from you via twitter ${ }^{8}$ or the JAAS blog. ${ }^{9}$

Let's keep in touch!

Martín Resano

\section{References}

1. F. Vanhaecke, J. Anal. At. Spectrom., 2015, 30, 1015-1016.

2. B. Sharp, J. Anal. At. Spectrom., 2006, 21, 1365-1366

3. http://pubs.rsc.org/en/journals/articlecollectionlanding?sercode=ja\&them eid=fddd7f5e-0e19-44fd-bb33-8fbc16f55392, last accessed in November 2016.

4. http://blogs.rsc.org/ia/2015/05/14/jaas-emerging-investigator-lectureshipawardees, last accessed in November 2016.

5. http://blogs.rsc.org/ia/2016/10/13/jaas-emerging-investigator-lectureshiprecipient/, last accessed in November 2016.

6. http://www.csi-conference.org, last accessed in November 2016.

7. http://blogs.rsc.org/ja/2016/09/22/top-10-reviewers-for-jaas/, last accessed in November 2016.

8. https://twitter.com/jaasnews, last accessed in November 2016.

9. http://blogs.rsc.org/ja/, last accessed in November 2016. 